\title{
PRESENCIA SABOYANA EN LA CORTE DE LOS PALEÓLOGOS (1326-1347)
}

\section{Galo Garcés Ávalos}

Universidad de Lima. Perú

Resumen: El propósito del presente artículo es analizar los aspectos de la presencia de cortesanos saboyanos en Bizancio tras la boda de Andrónico III Paleólogo con la princesa Giovanna de Saboya, conocida por los griegos como Ana de Lombardía (Avva $\tau\rceil \varsigma$ $\Lambda$ $\mu \beta \alpha \rho \delta\llcorner\alpha \varsigma)$, la cual tuvo un rol decisivo en el Imperio a la muerte de su marido en 1341, y se enfrentó a Juan Cantacuzeno en lo que se conoció como la Segunda Guerra Civil Bizantina (1341-1347), valiéndose no sólo de los nobles bizantinos leales a su hijo, Juan V, sino también de sus compatriotas saboyanos.

Palabras clave: Bizancio s. XIV - Guerra Civil Bizantina - Ana de Saboya - Condado de Saboya.

\section{SAVOYARD PRESENCE IN THE COURT OF THE PALAEOLOGI (1326-1347).}

Abstract: The purpose of the present article is to analyze the aspects of the presence of Savoyard courtiers in Byzantium after the wedding of Andronikos III Palaiologos with the princess Giovanna of Savoy,

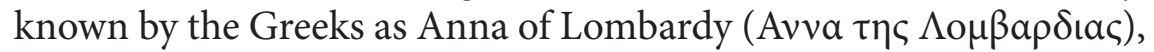
who had a decisive role in the Empire after the her husband's demise in 1341, and who confronted John VI Kantakouzenos in the conflict known as the Second Byzantine Civil War (1341-1347), where she not only relied on the Byzantine noblemen loyal to her son, John V, but also on her Savoyard countrymen.

Key words: Byzantium $14^{\text {th }}$ Century - Byzantine Civil War - Anna of Savoy - County of Savoy.

Recibido: 29.03.2014 - Aceptado:15.05.2014 


\section{Correspondencia: Galo Garcés Ávalos \\ galo_braganza_orleans@hotmail.com \\ 20090431@aloe.ulima.edu.pe \\ Facultad de Derecho - Universidad de Lima}

\section{${ }^{l} 16$ de agosto de 1324, Adelaida-Irene de Brunswick- CGrubenhagen, consorte del Co-emperador de Bizancio} Andrónico III Paleólogo (1328-1341), falleció en la ciudad tracia de Redesto. Su cuerpo fue enterrado en el Monasterio de Constantino Lips, en Constantinopla ${ }^{1}$. Por quince días su joven marido guardó riguroso luto, y al finalizar éstos su abuelo, el emperador Andrónico II, le recordó la necesidad de contraer un segundo matrimonio en aras de concebir un heredero al trono, dado que el hijo de Andrónico III e Irene había fallecido a los pocos meses de nacido. La doncella elegida fue Juana, hija de Amadeo V El Grande, conde de Saboya, y de su segunda mujer María de Brabante 2 .

${ }^{1}$ LAIOU (1972): 302; BARKER (2009): 52; TALBOT (2001): 337, analiza las construcciones realizadas en Constantinopla durante el reinado de Andrónico II Paleólogo, y asimismo menciona los monasterios donde miembros de la familia imperial fueron enterrados. En Lips también serían enterrados el déspota Constantino Paleólogo -hijo preferido de Miguel VIII (1259-1282) -y el mismísimo Andrónico II, quien en sus últimos años, anciano y casi ciego, tomó el nombre monástico Antonio.

RUNCIMAN (1981): 275, atribuye la boda de Andrónico III y Adelaida de Brunswick a Yolanda de Montferrat, segunda mujer de Andrónico II, en tanto Adelaida era nieta de Alasia de Montferrat, hermana del marqués Guillermo V y tía de Yolanda. DABROWSKA (2008): 234, n. 16, rechaza de plano tal perspectiva, argumentando -razonablemente- que Yolanda detestaba a su hijastro Miguel IX, y es resulta casi imposible que orquestara el matrimonio del vástago de éste último. La autora explica que el motivo de la alianza fue el hecho que el padre de Adelaida, el duque Enrique de Brunswick, había sido excomulgado por el Papa Juan XXII y añade que no se requirió dispensa papal para dicho matrimonio.

En efecto, resulta sumamente interesante el rol de la diplomacia bizantina en los enlaces con princesas occidentales acaecidos durante la Era de los Paleólogos, teniendo en cuenta el número de consortes "latinas" de los emperadores de Bizancio en el periodo 1261-1453, a decir: Ana de Hungría (c. 1260-1281), Yolanda-Irene de Montferrato (c. 1274-1317), Adelaida-Irene de Brunswick (c. 1293-1324), Ana de Saboya (1306-1365), y Sofía Paleóloga de Montferrat ( $\dot{z}$ - 1434), sin contar enlaces de los déspotas de la última generación de príncipes Paleólogo con damas occidentales, como fue el caso del déspota Teodoro II de la Morea (1407-1443) con Cléope Malatesta de Pesaro.

2 LAIOU (1972): 302-303, en octubre de 1323 había fallecido el conde Amadeo V, y su hijo Eduardo de Saboya, habido con su primera mujer Sibila de Bâgé, heredó el condado 
Dentro del marco de una posible alianza con los gibelinos, la decisión de desposar a su nieto con la princesa saboyana fue tomada por el ya anciano Andrónico II. Él mismo había desposado como segunda esposa también a una princesa del Piamonte, Yolanda-Irene de Montferrat, a cuyo hijo Teodoro había legado el Marquesado de Montferrat, herencia de su orgullosa prosapia (los Aleramici), y había traído consigo al emperador de Bizancio sus derechos titulares a la Corona Latina de Tesalónica, fundada en el 1204 por su ancestro Bonifacio de Montferrat, líder de las huestes de la funesta Cuarta Cruzada ${ }^{3}$.

¿Qué se pretendía lograr mediante una alianza matrimonial con los Saboya? John W. Barker señala que la boda entre el joven Andrónico y la princesa piamontesa significaba una continuación por parte del Co-emperador de la política matrimonial de su abuelo, Andrónico II ${ }^{4}$. Resulta mucho más probable que el verdadero motivo de la boda con Juana de Saboya fuera el llegar a un mejor entendimiento con el Papado y los Reinos de Occidente, que hasta hace algunos años

y negoció el matrimonio de su medio hermana menor con el emperador bizantino. CARRONE (1837): 22-23, narra la historia del reinado de Amadeo V y de su hijo Eduardo, aunque menciona ciertos datos inexactos respecto a Juana (Giovanna). El autor asimismo indica como inexacta la creencia que Amadeo V habría contraído un tercer matrimonio a la muerte de su segunda esposa, con Alicia de Viena (¿Viennois?). Véase también ORIGONE (1998): 21-27, para la infancia de la joven Juana. Véase también el Apéndice II del presente artículo.

${ }^{3}$ Para la alianza bizantino-gibelina de 1325, véase LAIOU (1972): 302, quien señala además que ambos emperadores pudieron enterarse de la disponibilidad de la princesa saboyana como futura imperial consorte a través del hijo menor de Andrónico II, el marqués Teodoro de Montferrat, quien se encontraba en Constantinopla en junio o julio de 1325, visitando a sus familiares y buscando dinero para sus guerras en el Piamonte, donde tanto Saboya como Montferrato, estados gibelinos, combatían a las tropas de Roberto de Anjou, rey de Nápoles. Para Teodoro Paleólogo de Montferrat, véase LAIOU (1968): 386-420.

Para el segundo matrimonio de Andrónico II Paleólogo, véase FAILLER (1999): 225-235, y también CONSTANTINIDI-BIBIKOU (1950): 425-442, quien señala que Yolanda llegó a Bizancio ostentando la inexistente Corona de Tesalónica, derechos que más tarde reclamarían los descendientes de su hijo Teodoro de Montferrato, junto a los de Constantinopla y el Imperio en su totalidad, durante la Guerra Civil de 1341-1347.

${ }^{4}$ BARKER (2009): 52-53, brinda un excelente análisis comparativo de las bodas de los emperadores de Bizancio con princesas latinas, principalmente enfocado en los matrimonios de la dinastía de los Paleólogo. 
habían visto con beneplácito las ambiciones de Carlos de Valois sobre Constantinopla y los territorios del otrora Imperio Latino ${ }^{5}$.

Por otro lado, encontramos que ante el reproche del Papa Juan XXII por permitir que su hermana sea desposada por el emperador de Bizancio, el conde Eduardo de Saboya-hermanastro de Juana - argumentaba que la boda podría resultar en la conversión de Andrónico III a la Fe Católica, cosa que el Pontífice estimó loable más probablemente en vano ${ }^{6}$. La boda de Ana de Saboya y Andrónico III sería, en efecto, el inicio del rol de Saboya como uno de los nexos entre el Papado y Bizancio.

¿Hasta qué punto fue beneficiosa esta alianza matrimonial? En la primera etapa, que cubre los años 1326-1341 y que es analizada en el presente artículo, encontramos que las ventajas no fueron muchas y que, pese a emparentar con la prestigiosa Casa de Saboya, Andrónico III mantuvo relaciones tirantes con el Papado respecto al delicado asunto de la Unión de Iglesias.

Asimismo, encontramos que pese a ser una princesa de Saboya, la emperatriz Ana no contó con mayor apoyo de su tierra natal que su dama Isabelle de La Rochette, el hijo de ésta, Artaud de Montmayeur -quien combatió en las filas de Apocauco hasta 1343 -y el caballero Philippe de Saint-Germain, a quien Ana enviaría como embajador al Papa Clemente VI a fines de 1343, con la balanza inclinada a favor de Cantacuzeno en medio de la desastrosa guerra civil.

${ }^{5}$ LAIOU (1972): 202-242, explica detalladamente los planes de reconquista del Imperio Latino por parte de Carlos de Valois (1270-1325), esposo de Catalina de Courtenay, emperatriz de Constantinopla y nieta de Balduino II, último emperador latino, que había perdido la Ciudad en 1261.

${ }^{6}$ LAIOU (1972): 304, añade además que Juan XXII creía que en tanto el marido era más fuerte que la mujer, Ana irremediablemente sería asimilada a la Ortodoxia y finalmente abandonaría el Catolicismo. Asimismo, la autora añade que Saboya no era fanáticamente gibelina, y que en sus últimos años Amadeo $\mathrm{V}$ había tratado de establecer alianzas matrimoniales con Roberto de Nápoles y Carlos IV de Francia, líderes de la facción güelfa. En ese aspecto encontramos la notable diferencia entre las bodas de Andrónico II y Yolanda de Montferrat -cuya familia era gibelina-y la de Andrónico III con Ana de Saboya. 


\section{El cortejo de la futura emperatriz: la llegada de Ana de Saboya a Constantinopla.}

Los emisarios bizantinos enviados a pedir la mano de la

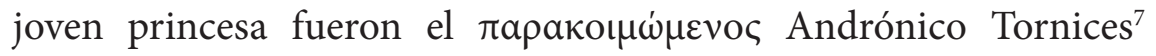

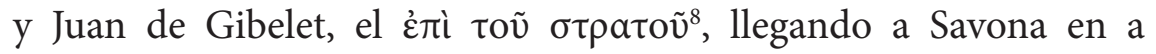
mediados de agosto de 1325, siendo escoltados a Chambéry, la capital del Condado de Saboya, por una guardia de honor enviada por el conde Eduardo, quien los recibió en el mes de septiembre de ese mismo año, junto a la futura novia.

Para el 22 de septiembre culminaron las negociaciones y Juana de Saboya, ahora llamada Ana tras adoptar la $\mathrm{Fe}$ Ortodoxa de su futuro marido, partió de su natal Saboya rumbo a Bizancio, quedándose en Savona de mediados de octubre a finales de noviembre, recibiendo un agasajo digno de reyes por parte de los genoveses gibelinos exiliados en la ciudad'. A fines de noviembre, Ana de Saboya partió rumbo a su nuevo hogar, y desembarcó en Constantinopla en el mes de febrero de 1326, escoltada por la siguiente comitiva ${ }^{10}$ :

- Guglielmo de Grancerio (o Guillermo de Grancerio), su capellán.

${ }^{7} \mathrm{Su}$ entrada en el Prosopographisches Lexikon der Palaiologenzeit (en adelante PLP) es la No 29122, Andrónico Comneno Ducas Paleólogo Tornices fue $\pi \alpha \rho \alpha \kappa o \iota \mu \omega ́ \mu \varepsilon v o \varsigma o$ paracoimómeno (oficial de la corte imperial)de 1324 a 1327.

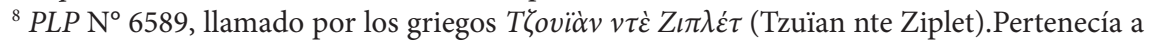
uno de los linajes más nobles del Reino de Chipre, tal y como señala LAIOU (1972): 303,

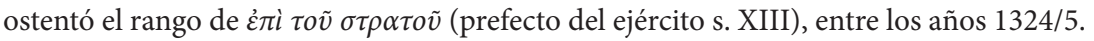
Para los señores de Gibelet, véase REY (1895): 398-422.

9 Véase NICOL (1993): 83; MURATORE (1909): 221-475, contiene la biografía más detallada de Ana de Saboya, y la más documentada; LAIOU (1972): 303, menciona cómo miembros de la familia Spínola, magistrados de Savona y cuya pariente Argentina Spínola era marquesa de Montferrato tras su boda con Teodoro Paleólogo, dieron la bienvenida a la futura emperatriz de Bizancio, en clara señal de favor y amistad para con el Imperio.

10 La comitiva que acompañó a la futura emperatriz de Bizancio es mencionada en MURATORE (1909): 267-270; ORIGONE (1998): 40; y CIBRARIO (1841): 9, la segunda versión de los nombres de los acompañantes de la princesa saboyana citados a continuación, provienen de ésta última fuente. 
- Andrea Bonuschristianus (o Andrés Buencristiano), tesorero pisano y encargado de las expensas del viaje y nupcias ${ }^{11}$.

- Stefano d'Andelot o Dandelet.

- Ugo de la Palu o Ugo de Palud, caballero.

- Aimone de Beauvoir, caballero.

- Pierre de la Baume o Pietro de la Baume, de la familia de los condes de Montrevel-en-Bresse, era señor de Valusin, Bailío de Bresse, de Bugey y de Novaleyse, fue el primero de los señores de Saboya en jurar lealtad al Conde Amadeo V, y en reconocer como heredera del Condado a la hija de Eduardo de Saboya y Blanca de Borgoña, la duquesa Juana de Bretaña. Se casó con Margarita de Vassalieu, viuda de Josselin, señor de Grolée, e hija de Étienne, señor de Vassalieu, la cual murió en el 1348 y fue enterrada en la Cartuja de Meyrieu, tras haberle dado cinco vástagos ${ }^{12}$.

- Enrico Bonzani o Arrighetto Bavzany, caballero.

- Pietro di Variset o Pietro de Variseto, caballero.

- Stefano Reynaudi o Stefano Reymond, preceptor en 1297 del conde Eduardo, de quien además controló los gastos ${ }^{13}$.

- Leonia e Isabella de La Rochette, damas. Hijas de François de La Rochette y de su mujer, Béatrix ${ }^{14}$. En el registro de adquisiciones y

${ }^{11}$ ORIGONE (1998): 37.

${ }^{12}$ DE LA CHESNAYE-DESBOIS (1771): 93, era hijo de Étienne de la Baume, caballero en 1272, y de su mujer Margarita de la Baulme.

El 21 de marzo de1329, Juana de Saboya, hija única del conde Eduardo y de su mujer Blanca de Borgoña, había sido desposada por el duque Juan III de Bretaña en la Catedral de Chartres, y a la muerte de su padre en noviembre de ese mismo año, reclamó para sí la corona de Saboya. Sin embargo, los grandes barones y prelados del Condado reconocieron como sucesor a su tío Aimone, el cual en 1322 había recibido de su padre la tierra de Bâgé como infantado, y asimismo había sido designado sucesor de su hermano en tanto éste no tuviera descendencia masculina, dado que la Ley Sálica regía la sucesión saboyana. Para mayores detalles véase CIBRARIO (1844): 26-29, y también VERONA (1859): 91. De su matrimonio con el duque de Bretaña, Juana de Saboya no tuvo descendencia, y a la muerte de éste en 1341, se desencadenó el conflicto conocido como la Guerra de Sucesión Bretona (1341-1364). Para mayores referencias véase CASSARD (1994): 17-34.

${ }^{13}$ CIBRARIO (1839): 4.

${ }^{14}$ BERNARD (1969): 250, menciona a los padres de Isabella de La Rochette. 
pérdidas territoriales de la Casa de Saboya realizado por el Conde Luigi Cibrario, encontramos que Ugo de la Rochette adquirió el castillo de Chambéry de manos de Amadeo $\mathrm{V}^{15}$.

- Margarita Bonnivard y la esposa de Reynaudi, damas ${ }^{16}$.

- Una hija de Bonnivard y una hija de Reynaudi, damiselas ${ }^{17}$.

Asimismo, le acompañaron tres franciscanos o frailes menores, veintitrés jóvenes escuderos y quince sirvientes. Sin embargo, el viaje, acaecido en medio del invierno, había mellado la salud de la joven princesa y enfermó gravemente, llevándose a cabo la boda en el mes de octubre, donde fue coronada emperatriz.

El elegante cortejo de la futura consorte de Andrónico III fascinó a los bizantinos, quienes la recibieron con igual magnificencia. El joven emperador encantó a los caballeros saboyanos, dado su gusto por las justas y los torneos, tan típicos en la tradición de la caballería occidental, y que antaño habían fascinado de igual forma al gran emperador que fue Manuel I Comneno (1143-1180) ${ }^{18}$. El

${ }^{15}$ CIBRARIO (1869): 29.

${ }^{16}$ MURATORE (1909): 258; ORIGONE (1998): 40. Sobre Bonnivard, Giovanni Bonnivard "El Joven" escoltó a la futura emperatriz en su trayecto de Chambéry a Savona, de acuerdo a lo señalado por ORIGONE (1998): 37-38, citando a MURATORE (1909): 260-266.

${ }^{17}$ MURATORE (1909): 258; ORIGONE (1998): 40.

${ }^{18}$ CINNAMO,99, señala lo siguiente: "Cuando el emperador Manuel asumió el imperial oficio, se preocupó sobre cómo los romanos podrían mejorar su armamento para un futuro. Anteriormente, era costumbre para ellos estar armados con escudos redondos y en su mayor llevar carcajes y decidir las batallas por los arcos, más él les enseñó a portar unos [escudos] que alcanzaran sus pies, y los entrenó para blandir largas lanzas y practicar hábilmente la equitación. Deseando darse un respiro de los preparativos para la guerra, estaba frecuentemente acostumbrado a practicar la equitación; haciendo la simulación de una batalla, colocaba formaciones opuestas una a otra. Por tanto cargando con lanzas romas, practicaban maniobras en armas. Por lo que en breve tiempo los romanos destacaron en temple entre francos e italianos. Por su parte el emperador no se mantuvo al margen de dichos conflictos, sino estaba dispuesto en primera línea, portando una lanza incomparable en longitud y tamaño. Puesto que, además de lo ya dicho, un estandarte de gran longitud se encontraba sujeto a ésta, que, como está dividido en ocho partes, es tradicionalmente llamado "de ocho pies de altura". En efecto se cuenta que Raimundo [de Poitiers, príncipe de Antioquía (1136-1149)], un hombre como el legendario Heracles, cuando vino a Bizancio, quedó sorprendido y consideró 
joven Andrónico no se quedó atrás, ganándose la admiración de un gran campeón -a decir de Cantacuzeno- de no sólo Saboyanos, sino también de Francos y Germanos, a quienes describe como "los más grandes estudiosos de tales disciplinas" ${ }^{\prime 19}$.

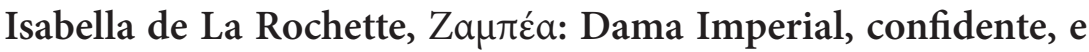 informante papal en Bizancio.}

En vida de Andrónico III, Ana de Saboya -o Ana de Lombardía, como la llama el cronista Nicéforo Gregoras -no jugó un papel político que se pueda considerar como relevante, dejando tales asuntos a Juan Cantacuzeno, hombre de confianza de su marido $-\mathrm{y}$ en quien desconfiaba profundamente - y otros tantos cortesanos del entorno del emperador. Todas las esperanzas de que Ana convirtiera a Andrónico III al Catolicismo Romano fueron fútiles, en tanto que podríamos señalar que la princesa saboyana sufrió un proceso que bien podríamos definir como "bizantinización", adoptando la Fe Ortodoxa de forma íntegra, y lo cual le valió despectivos comentarios del cronista Brocardo a su matrimonio ${ }^{20}$.

el asunto algún truco. Acercándose al emperador, le pidió la misma lanza y escudo; tomándolos, se dio cuenta de la verdad y anunció su descubrimiento con sorpresa."

${ }^{19}$ CANTACUZENO, I, 205; LAIOU (1972): 304, comenta jocosamente que si bien campeón en la justas, Andrónico III se probó menos capaz en otras formas de combate, siendo derrotado por tropas turcas en Tracia poco después de su boda; NICOL (1994): 84, relata la fascinación de Andrónico III por la caballería occidental, teniendo como huéspedes en palacio a caballeros que le enseñaron a justar y acerca de los torneos, así como le acompañaron de cacería. A partir de ese momento, el emperador invitaba cada año a caballeros a Constantinopla, donde realizaba justas y torneos en los que él mismo participaba, ante la mirada desaprobadora de sus consejeros más antiguos, quienes veían con malos ojos tales señales de frivolidad.

${ }^{20}$ BROCARDO, 423-421, señala que Andrónico III era un hipócrita, mentiroso y beodo que había forzado a Ana en el matrimonio. DABROWSKA (2008): 223, menciona que dicho reporte iba dirigido como incentivo a una expedición militar a Felipe VI de Valois, rey de Francia (1328-1350), hijo de Carlos de Valois, cuya segunda esposa fue Catalina de Courtenay, emperatriz latina de Constantinopla, y el cual preparó una campaña de conquista de Bizancio que terminó en el fracaso. Para mayores detalles véase LAIOU (1972): 200-242, es la mejor fuente en tanto brinda un análisis impecable de los proyectos de conquista de Carlos de Valois sobre el Imperio Latino, y adjunta documentación inédita de la correspondencia de ciertos nobles griegos afectos a los emperadores latinos. 
Por su parte, la emperatriz dio a luz en el 1327 a una niña, María cuyo nombre cambió a Irene tras su boda-, a la cual comprometieron a la edad de cinco años con Miguel Asen IV, heredero del zar búlgaro Iván Alejandro ${ }^{21}$; en 1332, en la ciudad de Didimótico, al futuro Juan V Paleólogo (1341-1391) ${ }^{22}$; en 1337 a Miguel Porfirogénito ${ }^{23}$, rehén del rey serbio Esteban IV Uros Dušan (1331-1355) durante la Segunda Guerra Civil; y finalmente a María Paleologina, futura esposa de Francesco Gattilusio ${ }^{24}$, arconte de Lesbos y quien ayudaría a Juan $\mathrm{V}$ a recobrar Constantinopla de manos cantacuzenistas ${ }^{25}$.

El panorama político cambió por completo cuando en junio del año 1341, Andrónico III falleció víctima de una enfermedad que médicos en la actualidad han determinado como malaria crónica ${ }^{26}$. En su lecho de muerte, el emperador confió a su esposa e hijos al cuidado del hombre en quien había confiado durante todo su

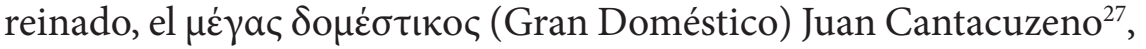
quien inmediatamente despachó mensajes a los gobernadores de las provincias avisándoles sobre la muerte del emperador, conminándolos a mantener su lealtad al joven heredero Juan V, y protegiendo a la familia imperial con apoyo de la Guardia Varenga ${ }^{28}$.

${ }^{21}$ BOŽILOV (1985): 192-197, №39 Михаил Асен. El príncipe búlgaro combatió a los turcos otomanos cuando éstos comenzaron a penetrar la frontera búlgara desde 1354, y en el 1355 pereció en una batalla que, si bien significó una derrota con grandes pérdidas para los búlgaros, puso freno a la invasión otomana hasta la muerte de su padre en el año 1371.

${ }^{22}$ Uno de los más recientes y completos estudios realizados sobre la vida de Juan V Paleólogo es el de RADIĆ (1993).

${ }^{23}$ PLP N ${ }^{\circ} 21521$. Sobre el envío del Porfirogénito como rehén a Dušan, véase GREGORAS, III, 181 y CANTACUZENO, III, 246. Véase también SOULIS (1984): 50 y GARCÉS (2011).

${ }^{24}$ Sobre la boda de María Paleologina y Francesco Gattilusio, véase MILLER (1913): 408. Sus descendientes gobernarían Lesbos y otras islas del Egeo y ciudades de la costa norte de Tracia hasta llegado el periodo de la conquista otomana.

25 NICOL (1967): 269-283, es quizá el mejor estudio hecho sobre la caída de Juan Cantacuzeno en 1354.

${ }^{26}$ LASKARATOS \& MARKETOS (1997): 106-109, analizan la muerte de Andrónico III basándose en los síntomas de la enfermedad que las crónicas mencionan, en especial Gregoras y Cantacuzeno.

${ }^{27}$ Los mejores estudios realizados sobre la vida y obra de Juan VI Cantacuzeno (1347-1354) son los de NICOL (1968): 35-103, Nº 22 y NICOL (1996).

${ }^{28}$ CANTACUZENO, I, 559-560; NICOL (1994): 85, recuerda que en el 1330, cuando Andrónico III se encontraba casi al borde de la muerte, había nombrado a Juan Cantacuzeno protector de su mujer e hijos. 
Los sucesos posteriores han sido relatados en numerosos estudios llevados a cabo a lo largo del siglo XX y XXI. Mientras Cantacuzeno salió con el ejército imperial rumbo a Tracia en julio de 1341, a defender la provincia de los enemigos del Imperio, el $\mu \dot{\varepsilon} \gamma \alpha \varsigma$

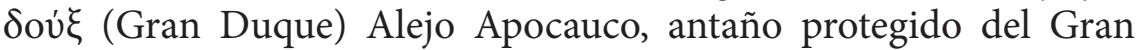
Doméstico, comandante de la flota que protegía los Dardanelos, trató de raptar al niño emperador y hacerse con el poder, sólo para terminar fracasando y refugiándose en su torreón fortificado en Epibatai ante el regreso de Cantacuzeno en septiembre de ese mismo año. Contrario al consejo de sus amigos más cercanos, el Gran Doméstico terminó perdonando a Apocauco ${ }^{29}$.

Cuando Cantacuzeno volvió a salir de la capital, Apocauco junto a un grupo de nobles y personajes importantes en la corte, entre

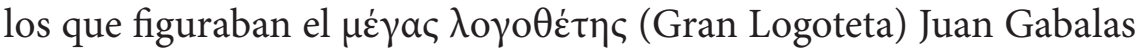

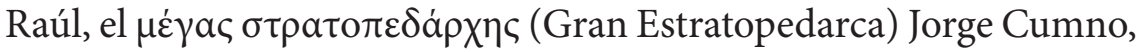
y el suegro de Cantacuzeno, Andrónico Paleólogo Asen, se hizo con el poder con apoyo del Patriarca Juan Calecas y la emperatriz Ana, quien desde siempre había desconfiado de Cantacuzeno, declarando traidor a éste último. En respuesta a tamaña traición, el 26 de octubre de 1341, el ejército proclamaba Emperador a Juan Cantacuzeno en Didimótico, recibiendo homenaje junto a su mujer Irene Asenina ${ }^{30}$.

Testigo de las múltiples conjuras y traiciones que acaecían en la corte del fallecido Andrónico III fue una dama saboyana, Isabella de la Rochette, la cual fue la única de las damas del cortejo que acompañó a Ana de Saboya de Chambéry a Constantinopla de la cual tenemos noticia de haber radicado en Bizancio tras 1326.

${ }^{29}$ Quizá los dos mejores estudios realizados sobre la Segunda Guerra Civil Bizantina (13411347) son los de MASTCHKE (1971) y NICOL (1972): 185-208, siendo éste último recuento una versión bastante puntual y concisa de los eventos más relevantes de la Guerra Civil en Bizancio.

${ }^{30}$ NICOL (1968): 47, señala además como miembros de la facción que siguió a Apocauco a los hermanos de Andrónico Asen, Isaac y Constantino; a Manuel Cantacuzeno Estrategópulo, y al hijo de una de las damas italianas de la emperatriz, Zampéa (Isabelle de La Rochette), llamado por los griegos 'A $\rho \tau \tilde{\omega} \tau o \varsigma$, y de quien el autor piensa su nombre real fue Odoardo, tema que analizaremos más adelante. 


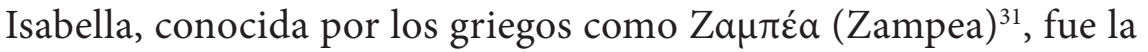
dama que mayor influencia tuvo en la Emperatriz, y se ganó elogios por parte de Juan Cantacuzeno dada su inteligencia y cultura. La magnitud de la influencia de Isabella llegó a oídos del Papa Clemente VI (1342-1352), cuarto de los Pontífices en residir en Aviñón, con el cual mantenía correspondencia, y a quien recomendó ejercer sus influencias en el retorno de los "cismáticos griegos" al seno de la Iglesia Católica ${ }^{32}$.

Un dato que muy pocos historiadores sobre la época mencionan y que merece ser divulgado en el presente artículo, es la identidad del esposo de Isabella. Parece probable que antes de partir a Bizancio, Isabella de la Rochette había sido desposada por el caballero Guigues de Montmayeur, poseedor de numerosas tierras en Saboya, con el cual tuvo dos hijos: Arthaud de Montmayeur y Rolet de Montmayeur, tal y como revela el estudio del Abbé Bernard sobre los orígenes feudales en Saboya y el Delfinado ${ }^{33}$.

Como se aprecia de los párrafos precedentes, encontramos que Isabella de la Rochette mantuvo una gran influencia en la Corte de Constantinopla durante el periodo de la Regencia de Ana de Saboya (1341-1347). Encontramos que en torno a ella, a Philippe de Sainte-Germain y al canónigo de Negroponte (Eubea), Bartolomé de

${ }^{31}$ PLP N ${ }^{\circ}$ 6446, fue dama de corte de Ana de Saboya de 1326 a 1347, llamada por Cantacuzeno TZAMPÉA, en CANTACUZENO, I, 205, apreciando su inteligencia y extraña cultura. MURATORE (1909): 125, brinda datos sobre su persona. NICOL (1994): 84, nos menciona su estadía en Bizancio al igual que la de otros caballeros saboyanos que ganaron la estima de Andrónico III.

32 Para una breve reseña sobre el Pontificado de Clemente VI (1342-1352) véase BAUMGARTNER (2003): 51-52. GAY (1904): 46, da la referencia exacta de la carta en la cual Clemente VI recomienda a Isabella luchar por la causa de la Unión de las Iglesias;GALLAND (1998): 200, y LEMERLE (1957): 184, n. 3, señala que el Papa Clemente VI felicitó a Isabella de La Rochette por su celo al momento de colaborar con la conversión de los griegos. Asimismo, menciona al caballero Philippe de SaintGermain, a quien Ana de Saboya envió como emisarioal Papa en octubre de 1343.

${ }^{33}$ BERNARD (1969): 350. Curiosamente casi ningún historiador sobre el periodo menciona al marido de Isabella, padre de Artaud, quien sería parte de las filas adeptas a la Regencia de Ana de Saboya, como MURATORE (1909), NICOL (1994), LEMERLE (1957), e incluso el PLP. 
Roma, giraba la comunicación entre la Emperatriz y el Gran Duque Apocauco, con el Papa Clemente $\mathrm{VI}^{34}$.

Para los últimos meses del año 1346, la suerte de la guerra estaba echada. La isla de Quíos, importante punto comercial del Imperio, había sido capturada por los genoveses y desde Selibria (actual Silivri, Turquía), Juan Cantacuzeno, quien ya había sido coronado Basileus en Adrianópolis por el Patriarca Lázaro de Jerusalén en mayo de ese mismo año, aguardaba la pronta rendición de la Ciudad, en donde Ana de Saboya -cuya Regencia había conocido el declive con el asesinato de Apocauco en 1345- empezaba a dialogar con los partidarios cantacuzenistas y deponía en Sínodo al Patriarca Juan Calecas el 1 de febrero de 1347, entrando Cantacuzeno en Constantinopla al día siguiente. Sin embargo, Ana de Saboya se rehusó a dialogar con el antiguo Gran Doméstico y encabezó una enconada resistencia desde el Palacio de las Blaquernas, y recién el 15 de febrero la emperatriz y Cantacuzeno llegaron a términos. Juan V Paleólogo, de quince años de edad, desposaría a Helena, hija de Cantacuzeno, y ambos serían Co-emperadores por 10 años, teniendo Cantacuzeno preeminencia como "Emperador mayor", y transcurrido ese plazo gobernarían juntos el Imperio como colegas ${ }^{35}$.

${ }^{34}$ LEMERLE (1957): 184, lo llama Bartolomé de Urbe. MILLER (1975) A: 251, señala que Bartolomé era canónigo de la Catedral de Negroponte y vicario del Patriarcado Latino de Constantinopla. Desde 1343 fue parte de las negociaciones entre el Papa Clemente VIy el Imperio Bizantino, y asimismo fue asiduo partidario de la Unión de Iglesias, de acuerdo a LOENERTZ (1953): 184, 189-190.

${ }^{35}$ Para la conquista de Quíos, el 15 de junio de 1346, véase MILLER (1975) B: 132-138, en donde el autor hace el mejor recuento de la conquista de la isla por el genovés Simón Vignosi, quien días atrás se había reunido con el Delfín Humberto de Vienne, líder de la Cruzada de Esmirna.

NICOL (1972): 206-207, en el sábado de Pascua (16 de abril) de 1346, Dušan había sido coronado "Emperador de Serbios y Griegos" en Skopje, por el Arzobispo de la Iglesia Autocéfala de Serbia, que fue inmediatamente elevado a Patriarca. Aquello le valió la excomunión por parte del Patriarca Juan Calecas. Curiosamente, casi un mes después era Cantacuzeno coronado en Adrianópolis.

DUCAS, 75, nos describe la enconada resistencia de la emperatriz Ana de la siguiente forma: "La emperatriz Ana se rehusó a rendirse y se encerró en el palacio con su hijo y algunos pocos soldados. En protesta vehemente repetía sin cesar "iSe ha cometido una injusticia conmigo!'”. Véase también NICOL (1994): 91-92. 
La entrada de Cantacuzeno en la Ciudad significó la partida de Isabella a Occidente. Los cronistas de la época no han registrado la reacción de la emperatriz Ana ante la partida de su confidente y dama de mayor confianza desde su llegada a Bizancio. Isabella de La Rochette había radicado en Bizancio aproximadamente dos décadas al lado de la viuda de Andrónico III, y al partir de la Ciudad informó directamente al Papa sobre el ascenso al poder de Juan Cantacuzeno ${ }^{36}$.

Seguidamente, en septiembre de 1437, Cantacuzeno enviaría una embajada al Papa encabezada por el protovestiario Jorge Espanópulos, Nicolás Sigeros, y el caballero auvernés François de Pertuxo ${ }^{37}$, con el objetivo de concretizar una alianza contra los Turcos, y también con el objetivo de limpiar su imagen y desmentir su supuesta amistad con los Otomanos, cuyas actividades en la guerra ya eran bien conocidas. Cantacuzeno nos relata:

"Cuando los embajadores explicaron al Papa el porqué de su visita, él mismo tomó la narración y contó todo exactamente como si en persona hubiera estado presente durante la guerra. Los embajadores se encontraban maravillados y preguntaron cómo sabía tales cosas de forma tan precisa. El Papa les dijo que había oído de ellas de Isabella de Saboya quien estaba con la emperatriz en Bizancio desde el preciso inicio de la guerra hasta el final. Después que el emperador tomó Bizancio, ella partió rumbo a casa, y cuando se encontró con el Papa le contó exactamente todo tal y como pasó, sin ocultar nada. El Papa elogió al emperador y rezó por él, puesto que, cuando había derrotado a sus enemigos en el campo de batalla, no se comportó con mezquindad o de forma innoble ni guardó malicia alguna contra aquellos que lo habían agraviado, incluso cuando él mismo había sido injustamente atacado en guerra, había sido

${ }^{36}$ CANTACUZENO, III, 55.

${ }^{37}$ SETTON (1976): 213, en este viaje, Nicolás Sigeros, pretor de la plebe acorde a Cantacuzeno (MILLER (1975) A: 188-189), trabaría amistad con Petrarca en enero de 1348, en Verona. François de Pertuxo (du Pertuis?) fue por su parte un caballero oriundo de Auvernia al servicio de Cantacuzeno. 
acusado por los sicofantes, y había soportado tales horrores durante la guerra, y todo esto a manos de aquellos que se habían beneficiado mucho de él (...) Especialmente lo elogió por unir en matrimonio a su hija con el joven emperador y entregarle su imperial patrimonio"38.

De la narración de Cantacuzeno, determinamos que Isabella abandonó Constantinopla después del 28-29 de mayo de 1347, fecha en la que Juan V Paleólogo desposó a Helena Cantacuzena, celebrada ocho días después de la coronación de Juan Cantacuzeno por el patriarca Isidoro ${ }^{39}$, e informó al Pontífice de lo ocurrido tras el ascenso del rebelde al trono.

Favoritos y embajadores: 'a $\alpha \tilde{\omega} \tau 0 \varsigma$ y Philippe de Saint-Germain.

'A $\tau \tilde{\omega} \tau \tau$, como llamaban los griegos al caballero saboyano Arthaud (o Artaud) de Montmayeur, llamado por Donald M. Nicol Odoardo, hijo de Isabella de la Rochette y de Guigues de Montmayeur, perteneció al bando de los lealistas a la Regencia de Ana de Saboya tras el ascenso al poder de Alejo Apocauco en Constantinopla en el año 1341. Tenía un hermano, Rolet, quien estudiaba en París a expensas del Conde de Saboya. Su padre se encontraba probablemente fallecido alrededor del año 1327, es decir, aproximadamente al año en que Ana de Saboya llegara a Bizancio ${ }^{40}$.

Arthaud, en tanto hijo de la amiga más cercana a la Basilisa, se mantuvo en la corte de Bizancio y durante las campañas contra el rebelde Cantacuzeno, se unió a las filas del ejército de la Regencia, entre las cuales figuraban Juan Vatatzés, Guy de Lusignan, arconte de Serres, Miguel Monómaco, gobernador de Tesalia, los hermanos Andrónico y Tomás Paleólogo, entre otros nobles y comandantes militares de la época. Arthaud, tal y como señala Jules Gay -quien lo llama Édouard, Eduardo - gozó de gran favor por parte de la Regente ${ }^{41}$.

\footnotetext{
${ }^{38}$ MILLER (1975) A: 188-190.

${ }^{39}$ NICOL (1968): 136.

${ }^{40}$ BERNARD (1969): 350.

${ }^{41}$ CANTACUZENO, II, 123-126, narra su participación en las filas de los partidarios a la Regencia de Ana de Saboya; Su entrada en el PLP es la Nº 1447; GAY (1904): 46.
} 
De acuerdo al Abbé Bernard, y en tanto el Prosopographisches Lexikon der Palaiologenzeit no brinda mayor noticia sobre Arthaud, señalamos que éste falleció el 6 de noviembre de 1343, y que los bienes que dejó fueron recogidos por su madre, ya viuda, de la diócesis de Constantinopla ${ }^{42}$. Es muy probable que Arthaud falleciera en algún encuentro bélico con las tropas leales a Juan Cantacuzeno.

Por otro lado, Philippe de Saint-Germain fue uno de los caballeros saboyanos más leales a la emperatriz Ana, quien le confió el envío de una carta al Papa Clemente VI en Aviñón donde le informara acerca de la disposición del joven heredero al trono de Bizancio, Juan V, de la propia emperatriz, del Gran Duque Apocauco y del Patriarca Calecas de hacer regresar a los "cismáticos griegos" al seno de la Santa y Romana Iglesia. Por su celo y labor para alcanzar la Unión de las Iglesias y el retorno de los Bizantinos al Catolicismo Romano, SaintGermain recibió la misma felicitación que Isabella de la Rochette ${ }^{43}$.

A su regreso de Aviñón a Constantinopla, el caballero de SaintGermain portaba tres cartas de Clemente VI: Al Gran Duque Apocauco, quien había mostrado su buena disposición hacia la Unión, al Patriarca Juan Calecas, y a los arzobispos y obispos de los griegos, así como a los monjes del Monte Athos, de cuya influencia sobre el pueblo advirtió Saint-Germain ${ }^{44}$.

La deferencia de la emperatriz hacia los ya mencionados compatriotas suyos evidencia claramente dos factores interesantes en su actuación política: (i) la necesidad de contar con personas de confianza ajenas a la corte griega y sus influencias (ii) la necesidad de mantener de forma directa sus relaciones diplomáticas con el Papado y no a través de embajadores bizantinos (Philippe de Saint-Germain) y muy posiblemente, la de mantener un ojo sobre el ejército de la Regencia (Arthaud de Montmayeur). En ambos aspectos, la emperatriz se valía de personajes saboyanos para llevar

${ }^{42}$ BERNARD (1969): 350.

${ }^{43}$ GAY (1904): 46; GALLAND (1998): 200; LEMERLE (1957): 184, n. 3.

${ }^{44}$ GAY (1904): 47-49, describe la embajada de Philippe de Saint-Germain de Constantinopla a Aviñón, portando los mensajes de la Regencia al Pontífice. 
a cabo misiones de vital importancia de acuerdo a la política proUnionista que llevó a cabo a fin de conseguir la ayuda del Papa en su lucha contra Cantacuzeno. En tanto desconfiaba de los cortesanos bizantinos que pululaban en la Constantinopla de la Regencia, Ana de Saboya se valió de ciertos caballeros de su tierra natal para poder llevar a cabo misiones diplomáticas así como militares, lo cual resulta perfectamente entendible en medio del escenario de constantes traiciones y deserciones en la Segunda Guerra Civil Bizantina.

\section{Conclusiones}

Cabe definir el rol de los cortesanos saboyanos que permanecieron en Bizancio tras la boda de Ana de Saboya con Andrónico III Paleólogo (octubre de 1326) como el de agentes del Papa Clemente VI y partidarios de la Unión de Iglesias Católica y Ortodoxa para mediados y fines del siglo XIV. Isabella de la Rochette, en tanto dama y confidente de la emperatriz de Bizancio, mantuvo una posición muy privilegiada en la corte imperial y fue notable sus actividades en pro del acercamiento entre el Papa y la turbada corte de Constantinopla, donde tras 1341 la Regencia se encontraba en plena lucha contra Juan Cantacuzeno e inmersa en una caótica guerra civil, en la cual, a decir del propio Cantacuzeno: "A la muerte del joven Andrónico, se desató la peor guerra civil que los Romanos habían experimentado, un conflicto que destruyó casi todo, reduciendo al gran Imperio Romano a una débil sombra de lo que fue."

Por otra parte, tanto el hijo de Isabella, Arthaud de Montmayeur, y el caballero Philippe de Saint-Germain, fueron personas de confianza dentro del entorno de la emperatriz, el primero luchando contra los insurgentes cantacuzenistas y el segundo, como embajador personal de la emperatriz ante Su Santidad para expresarle la mayor disposición por parte de ésta hacia la Unión de las Iglesias, quizá esperando ayuda del Papado hacia la Regencia en Constantinopla frente a la rebelión de Cantacuzeno. Sin embargo, durante las denominadas "Cruzadas Esmirniotas" o "Cruzadas de Esmirna”, el Papa Clemente VI prohibiría tajantemente la intervención del Delfín Humbert 
II de Viennois (1312-1355), comandante en jefe de la Cruzada, en el conflicto griego, quizá por temor a que se repitiera otra vez un suceso similar a la lamentable Cuarta Cruzada (1204), desvirtuando de forma total la misión de lucha contra los piratas turcos de Umur de Aydin y despejar las aguas del Mar Egeo de la presencia de los agarenos.

Así pues, pese al celo y labor de los cortesanos saboyanos de la emperatriz por concretizar la Unión de Iglesias y erguir al Imperio como un baluarte católico frente a la amenaza de los turcos y la insurgencia de Cantacuzeno, dicho objetivo no fue logrado y para cuando los pedidos de auxilio por parte de los emperadores bizantinos llegaron a Occidente con toda su fuerza, ya era demasiado tarde y la Iglesia Católica, dividida por el Gran Cisma (1378), y los reinos occidentales, inmersos en guerras como la de los Cien Años (13371453), no se encontraban en condiciones de enviar ayuda a gran escala hacia una prácticamente aislada Constantinopla, y donde del Imperio Bizantino no quedaban más que hijuelas dispersas por los Balcanes ${ }^{45}$.

${ }^{45}$ El presente artículo va dedicado a la memoria del Prof. Jean-Christophe Cassard, de la Universidad de Bretaña Occidental y de Barry Duncan, de la Editorial de la Universidad de Harvard, quienes contribuyeron en gran medida al desarrollo de la presente investigación. Asimismo, este artículo no hubiera podido ser realizado sin la ayuda del profesor Timothy S. Miller, de la Universidad de Salisbury, quien tan generosamente compartió con el autor su traducción inédita al inglés de la Historia de Juan Cantacuzeno; a la profesora Alice-Mary Talbot, cuyos estudios sobre los Paleólogo resultaron bastante esclarecedores; al profesor John W. Barker, de la Universidad de Wisconsin, cuyo artículo sobre los matrimonios dinásticos en la Era de los Paleólogos es sumamente descriptivo; al profesor Charles M. Brand, quien compartió con el autor su traducción al inglés de la crónica de Juan Cinnamo; a Dimitris Apostolidis (Kavala, Grecia) por compartir conmigo sus fuentes sobre la historia del Imperio Bizantino en los siglos XIV-XV; al profesor Frederic J. Baumgartner, por compartir con el autor su conocimiento acerca de los Papas en Aviñón; a Michał Kozłowski, por ayudar al autor a conseguir los artículos de la Prof. Dabrowska sobre los matrimonios y el rol de la emperatriz durante la Dinastía Paleólogo; a Sandra Rovegno (Universidad de Lima), quien gentilmente diseñó para el presente artículo el mapa del Condado de Saboya en el siglo XIV; a mis amigos de siempre, Guilhem W. Liberali, Eva Latorre Broto, y Rolando Castillo, quienes desde la adolescencia impulsaron en mí el investigar y conocer más acerca de la fascinante historia de Bizancio, y que posteriormente devino en mi interés por los Paleólogo y el declive del Imperio, mi eterno agradecimiento a ellos. Asimismo, no se habría podido concluir la investigación del presente artículo sin el constante apoyo de mi madre, María del Carmen Ávalos, mi más grande benefactora y a mi padre Galo Garcés Lama. 


\section{APÉNDICE I.}

\section{DOMINIOS DE LA CASA DE SABOYA (SIGLO XIV).}

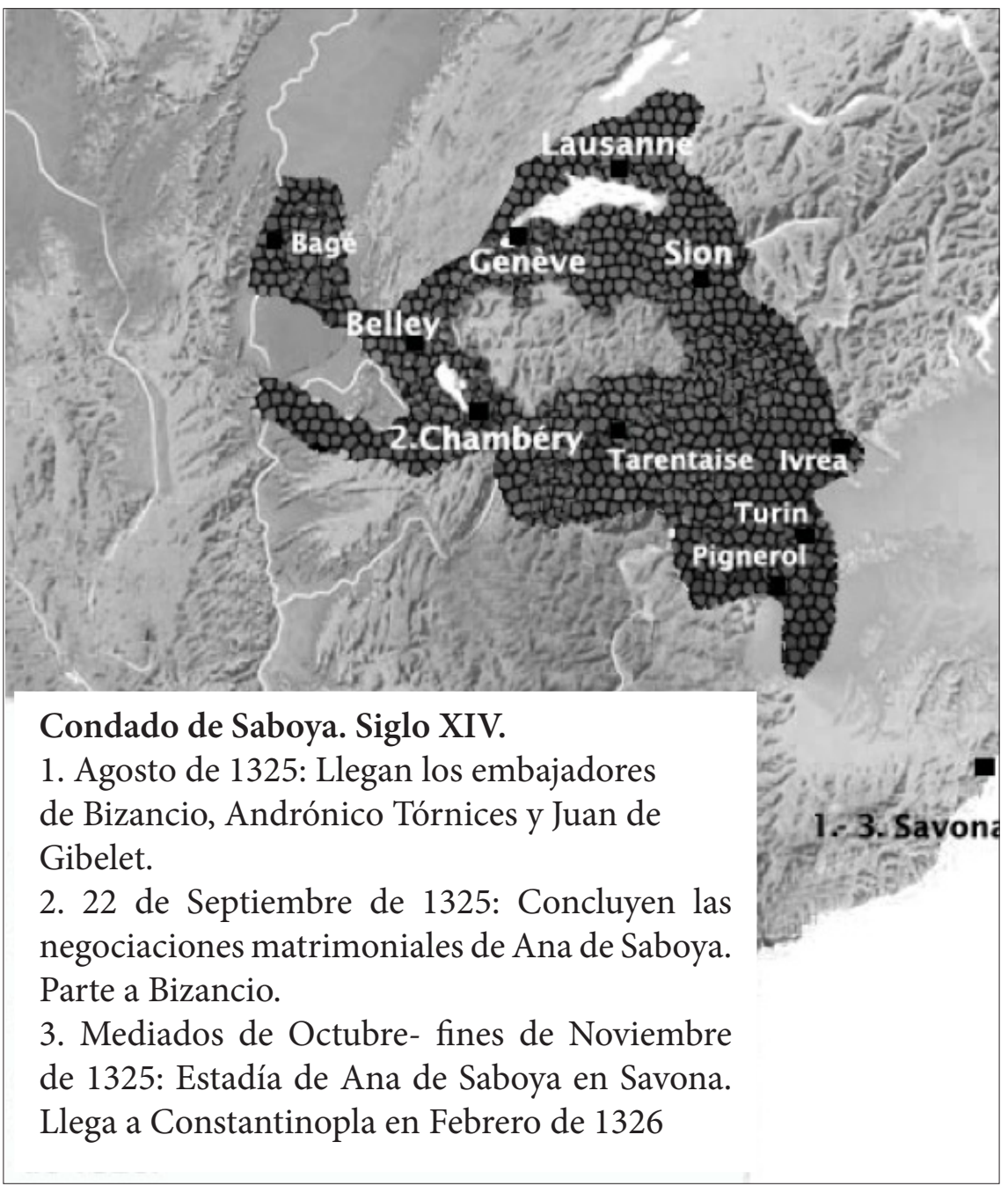

${ }^{46}$ El presente mapa de los dominios de la Casa de Saboya en el siglo XIV fue diseñado por Sandra Rovegno (Universidad de Lima), a quien agradezco enormemente su apoyo con el diseño del presente gráfico y las precisiones en el mapa sobre las negociaciones matrimoniales entre Ana de Saboya y Andrónico III Paleólogo. 


\section{Bibliografía}

BARKER (2009) = BARKER, John W. "Thoughts on Byzantine Dynastic Marriage Policies: Or, Were the Palaiologoi Really Italians?" en ALCHERMES, Joseph D. (Edit.) ANA@HMATA EOPTIKA: Studies in Honor of Thomas F. Mathews, Verlag Philipp von Zabern, Mainz am Rhein, 2009, pp. 47-56.

BAUMGARTNER (2003) = BAUMGARTNER, Frederic J. Behind Locked Doors: A History of Papal Elections. Palgrave Macmillan, New York, 2003.

BERNARD (1969) = BERNARD, Félix. Les Origines féodales en SavoieDauphiné: la vie et les rapports sociaux d'alors, Impr. Guirimand, Grénoble, 1969.

BOŽILOV (1985) = BOŽILOV, Ivan. Фамилията на Асеневци (1186-1460) [La Familia de los Asen (1186-1460)], Academia Búlgara de Ciencias, Sofía, 1985.

BROCARDO = BROCARDO, Directorium ad passagium faciendum, en Recueil des historiens des croisades, Documents Arméniens II, Paris, 1906, pp. 423-431.

CARRONE (1837) $=$ CARRONE, Felice. Tavole genealogiche della Real Casa di Savoia descritte ed illustrate da Felice Carrone Marchese di S. Tommaso. Presso Giuseppe Bocca Libraio di S. S. M. R., Torino, 1837.

CANTACUZENO = CANTACUZENO, Juan \& L. SCHOPEN (Ed.). Ioannis Cantacuzeni Eximperatoris Historiarum Libri IV. Vol I-III. Corpus Scriptorum Historiae Byzantinae, Bonn, 1828-1832.

CASSARD (1994) = CASSARD, Jean-Christophe. Charles de Blois: 1319-1364, Duc de Bretagne et Bienheureux. Centre de recherche bretonne et celtique, Brest, 1994.

CIBRARIO (1839) = CIBRARIO, Luigi. Dei Governatori, dei Maestri et delle Bibliotheche de Principi di Savoia fino ad Emmanuele Filiberto, et d'una Enciclopedia da questo principe incominciata, Stamperia Reale, Torino, 1839. 
CIBRARIO (1841) = CIBRARIO, Luigi. Opuscoli del Cav. Luigi Cibrario. StabilimentoTipografico Fontana, Torino, 1841.

CIBRARIO (1844) = CIBRARIO, Luigi. Storia della Monarchia di Savoia, Volumen Terzo, Alessandro Fontana, Torino, 1844.

CIBRARIO (1869) = CIBRARIO, Luigi. Origine e progressi delle instituzioni della monarchia di Savoia: sino alla costituzione del regno d'Italia, I-II, M. Cellini, Firenze, 1869.

CINNAMO = CINNAMUS, John \& Charles M. BRAND (Tr.), Deeds of John and Manuel Comnenus, Columbia University Press, New York, 1976.

CONSTANTINIDI-BIBIKOU (1950) $=$ CONSTANTINIDIBIBIKOU, Helene, "Yolande de Montferrat, Impératrice de Byzance," L'Hellénisme Contemporain 4 (1950), pp. 425-442.

DABROWSKA (2008) = DABROWSKA, Malgorzata,"Is there any room in the Bosphorus for a Latin lady?" en Byzantinoslavica 66 (2008), pp. 229-241.

DE LA CHESNAYE-DESBOIS (1771) = DE LA CHESNAYEDESBOIS, François-Alexandre Aubert. Dictionnaire de la noblesse, contenant les généalogies, l'histoire et la chronologie des familles nobles de France, Volumen 2, La VeuveDuchesne, Paris, 1771.

DUCAS = DOUKAS, Michael \& Harry J. MAGOULIAS, Decline and fall of Byzantium to the Ottoman Turks: An annotated translation of "HistoriaTurco-Byzantina", Detroit State University Press, Detroit, 1975.

FAILLER (1999) = FAILLER, Albert, "Le second mariage d'Andronic II Palaiologos," en Revue des études byzantines (REB) 57 (1999), pp. 225-235.

GALLAND (1998) = GALLAND, Bruno. Les papes d'Avignon et la Maison de Savoie 1309-1409, Ecole française de Rome, Roma, 1998. GARCES (2011) = GARCÉS ÁVALOS, Galo. «A Note on Michael the Porphyrogenitus, son of Andronikos III Palaiologos ( ${ }^{\star} 1337$ +1352).» Disponible de consulta en: http://www.medievalists. net/2012/08/05/a-note-on-michael-the-porphyrogenitus-son-of- 
andronikos-iii-palaiologos-1337-1352/; http://www.academia. edu/1508584/_A_Note_on_Michael_the_Porphyrogenitus_ son_of_Andronikos_III_Palaiologos_1337-_1352_-_Article_ presented_to_Byzantinoslavica.

GAY (1904) = GAY, Jules. Le pape Clement VI et les affaires d'Orient, Librairie Georges Bellais, París, 1904.

GREGORAS = GREGORAS, Nicéforo \& L. SCHOPEN (Ed.) Nicephori Gregorae Byzantina Historia, Vol. I-II. Corpus Scriptorum Historiae Byzantinae, Bonn, 1829-1830.

LAIOU (1972) = LAIOU, Angeliki E. Constantinople and the Latins: Foreign Policy of Andronicus II, 1282-1328, Harvard University Press, Cambridge Mass., 1972.

LAIOU (1968) = LAIOU, Angeliki E. "A Byzantine Prince Latinized: Theodore Palaeologus, Marquis of Montferrat," en Byzantion 38 (1968), pp. 386-410.

LASKARATOS \& MARKETOS (1997) = LASKARATOS, J. \& S. MARKETOS, "The fatal disease of the Byzantine Emperor Andronicus III Palaeologus (1328-1341 A.D.)", in Journal of the Royal Society of Medicine, 90 (1997), pp. 106-109.

LEMERLE (1957) = LEMERLE, Paul. L'Émirat d'Aydin, Byzance et l'Occident: Recherches sur "La Geste d'Umur Pacha. Presses Universitaires de France, Paris, 1957.

LOENERTZ (1953) = LOENERTZ, Raymond-Joseph. "Ambassadeurs grecs auprès du pape Clément VI (1348)" en Orientalia Christiana Periodica vol. 19 (1953) pp. 178-196.

MATSCHKE (1971) = MATSCHKE, Klaus-Peter. Fortschritt und Reaktion in Byzanz im 14. Jahrhundert. Konstantinopel in der Burgerkriegsperiode von 1341-1354. Berliner Byzantinische Arbeiten /42, Berlín, 1971.

MILLER (1975) A = MILLER, Timothy S. The History of John Cantacuzenus (Book IV): Text, Translation and Commentary, Catholic University of America, Washington D. C., 1975 "inédita." 
MILLER (1975) B = MILLER, Timothy S. "Chios, Byzantium and the Genoese (1346-1352)", en Byzantine studies II, 2, (1975), pp. 132-138.

MILLER (1913) = MILLER, William. "The Gattilusj of Lesbos (13551462)" in ByzantinischeZeitschrift 22 (1913), pp. 406-477.

MURATORE (1909) = MURATORE, Dino. "Una principessa sabauda sul trono di Bisançio, Giovanna di Savoia, impératrice Anna Paleologina." en Mémoires de l'Académie de Savoie, Ser. 4, Vol. XI (1906), pp. 1-256.

NICOL (1996) = NICOL, Donald M. The Reluctant Emperor: A Biography of John Cantacuzene, Byzantine emperor and monk, c. 1295-1383, Cambridge University Press, Cambridge,1996.

NICOL (1994) = NICOL, Donald M. The Byzantine Lady. Cambridge University Press, Cambridge 1994.

NICOL (1972) = NICOL, Donald M. The Last Centuries of Byzantium, 1261-1453. Cambridge University Press, Cambridge, 1993.

NICOL (1968) = NICOL, Donald M. The Byzantine family of Kantakouzenos (Cantacuzenus): ca. 1100 - 1460; a genealogical and prosopographical study, Dumbarton Oaks, Washington D. C., 1968. NICOL $(1967)=$ NICOL, Donald M. "The Abdication of John VI Cantacuzene" en Byzantinische Forschungen vol. 2 (1967) pp. 269-283. ORIGONE (1998) = ORIGONE, Sandra. Giovanna di Savoia, alias Anna Paleologina: Latina a Bisanzio (c. 1306 - c. 1365), Jaca Books, Milano, 1998.

PLP = TRAPP, Erich et. al, Prosopographisches Lexikon der Palaiologenzeit (PLP) Österreichische Akademie der Wissenschaften, Viena, 1976-1996.

REY (1895) = REY, E., "Les seigneurs de Giblet" en Revue de l'Orient latin 3 (1895), pp. 398-422.

RUNCIMAN (1981) = RUNCIMAN, Steven, "The Marriages of the Sons of the Emperor Manuel II" en Rivista di studi bizantini e slavi 1 (1981), pp. 273-282. 
SETTON (1976) = SETTON, K. M. The Papacy and the Levant, 12041571: Vol. I The thirteenth and fourteenth centuries. American Philosophical Society, Philadelphia, 1976.

SOULIS (1984) = SOULIS, G. C. The Serbs and Byzantium during the reign of Tsar Stephen Dusan (1331-1355) and his successors, Dumbarton Oaks Library and Collection, Washington D. C., 1984. TALBOT (2001) = TALBOT, Alice-Mary Maffry, "Building activity in Constantinople under Andronikos II: the role of women patrons in the construction and restoration of the monasteries" en NECIPOGLU, Nevra (Edit.) Byzantine Constantinople: Monuments, topography and everyday life, Brill, Leiden, 2001, pp. 329-343.

VERONA (1859) = VERONA, Agostino. Storia della Monarchia di Savoia, Unione Tipografico-Editrice, Torino, 1859. 